CALIMAN, F.R.B.; SILVA, D.J.H.; FONTES, P.C.R.; STRINGHETA, P.C.; MOREIRA, G.R.; CARDOSO, A.A. Avaliação de genótipos de tomateiro cultivados em ambiente protegido e em campo nas condições edafoclimáticas de Viçosa. Horticultura Brasileira, Brasília, v.23, n.2, p.255-259, abr-jun 2005.

\title{
Avaliação de genótipos de tomateiro cultivados em ambiente protegido e em campo nas condições edafoclimáticas de Viçosa
}

\author{
Fabiano Ricardo B. Caliman; Derly José H. da Silva; Paulo Cezar R. Fontes; Paulo César Stringheta; \\ Gisele R. Moreira; Antônio Américo Cardoso \\ UFV, 36571-000 Viçosa-MG; E-mail: caliman@vicosa.ufv.br; derly@ufv.br; pacerefo@ufv.br; aacardoso@ufv.br; stringap@ufv.br; \\ grmoreira@hotmail.com
}

\section{RESUMO}

Avaliou-se a influência da temperatura, umidade relativa do ar, luminosidade e seus efeitos na produtividade do tomateiro cultivado em ambiente protegido e no campo. Foram conduzidos dois experimentos em diferentes ambientes de janeiro a maio de 2002. A cultivar Santa Clara, o híbrido Carmen e o acesso BGH-320 do Banco de Germoplasma de Hortaliças da UFV, foram utilizados em ambos os experimentos. $\mathrm{O}$ experimento em ambiente protegido foi conduzido em estufa tipo capela e o do campo sob condições naturais. No ambiente protegido foram registradas maiores umidade relativa do ar e temperatura e menor luminosidade em relação ao cultivo no campo. Observou-se, de uma maneira geral, maior produtividade das cultivares quando as mesmas foram conduzidas sob cultivo protegido, com exceção do acesso BGH-320 cujas médias da produção comercial nos dois ambientes foram bastante similares. Com relação aos genótipos, o híbrido Carmen superou os demais no ambiente protegido. $\mathrm{O}$ acesso BGH-320 que no ambiente protegido foi inferior aos outros dois genótipos, no campo apresentou produção total superior à da cultivar Santa Clara e semelhante a do genótipo Carmen. No cultivo no campo, a produção comercial não diferiu entre os três genótipos.

Palavras-chave: Lycopersicon esculentum, temperatura, umidade relativa do ar, luminosidade, rendimento.

\section{ABSTRACT}

Assessment of tomato genotypes grown in protected environment and field conditions in Viçosa

The influence of the temperature, air humidity, brightness and their effects on tomato yield growth in protected environment and in the field were evaluated. Two experiments were carried out in different atmospheres from January to May 2002. The cultivar Santa Clara, hybrid Carmen and an accession BGH-320 from the Germplasm Vegetable Bank of Universidade Federal de Viçosa, Minas Gerais State, Brazil, were used in both experiments. The experiment under protected environment was carried out in a greenhouse type chapel and the other in the field, under natural conditions. In general higher production of fruits was observed on plants cultivated under protected environment than in open field. The Carmen hybrid exceeded the other genotypes in yield in the protected environment. Accession BGH-320 presented lower total yield under protected environment than the other two genotypes. In the field the accession BGH-320 presented higher total yield than Santa Clara cultivar and a similar yield than Carmen. In the field, the commercial yield did not differ among the three genotypes.

Keywords: Lycopersicon esculentum, temperature, air relative humidity, brightness, yield.

(Recebido para publicação em 25 de março de 2004 e aceito em 25 de janeiro de 2005)

$\mathrm{O}$ cultivo em ambiente protegido é uma eficiente forma de superar adversidades climáticas e maximizar a produtividade das plantas (MANRIQUE, 1993). Apesar da área cultivada nesse sistema ser ainda bastante reduzida, sua importância está relacionada à possibilidade de se produzir alimentos em épocas e ou regiões nas quais as condições climáticas são desfavoráveis, viabilizando o fornecimento de alimentos no período da entressafra (ANDRIOLO, 2000).

Alguns fatores são, de certa forma, controlados no ambiente protegido. Desta forma, possibilita-se a proteção das plantas de condições adversas de clima e solo como ventos, evapotranspiração, umidade relativa do ar e do solo, baixas temperaturas, radiação solar, efeito direto das chuvas, lixiviação de nutrientes, aeração do solo, chuvas de granizo entre outros (ANDRIOLO, 2000; VIDA et al., 2001).

Luz, temperatura e umidade relativa são importantes fatores que afetam a produtividade da cultura do tomateiro. A luz é essencial para a primeira etapa da cadeia de fixação do $\mathrm{CO}_{2}$, a fotossíntese, processo no qual é produzida energia bioquímica necessária ao crescimento e produção das culturas (Papadopoulos et al., 1997; Andriolo, 2000). Da mesma forma, a temperatura tem importante função no controle da velocidade das reações químicas celulares, as quais governam o crescimento e desenvolvimento da planta (COCKSHULL, 1992). Outro importante componente climático é a umidade relativa do ar, que pode afetar a transpiração da planta por interferir na condutância estomática. Indireta- mente, pode afetar a turgência dos tecidos alterando processos metabólicos ligados ao crescimento da planta, como por exemplo, a absorção de nutrientes (ANDRIOLO, 2000).

Além do clima, fatores de origem biótica podem afetar a produtividade do tomateiro, seja em cultivo protegido ou no campo. O período de molhamento foliar, seja por chuva ou por orvalho, a que as plantas geralmente são submetidas quando cultivadas no campo favorece a infecção e disseminação de doenças podendo causar grandes perdas na produção. Sem a adoção de um manejo de controle adequado, as pragas também podem causar danos consideráveis à cultura e queda na produção (GALLO et al., 2002).

Apesar da complexidade do sistema de produção, a agricultura visa 
Tabela 1. Produção total e comercial de frutos em genótipos de tomateiro cultivados em ambiente protegido e no campo. Viçosa, UFV, 2002.

\begin{tabular}{|c|c|c|c|c|c|c|}
\hline \multirow{2}{*}{ Genótipo } & \multicolumn{3}{|c|}{$\begin{array}{l}\text { Produção no ambiente protegido }{ }^{1} \\
(\mathrm{t} / \mathrm{ha})\end{array}$} & \multicolumn{3}{|c|}{ Produção no campo' (t/ha) } \\
\hline & Total & Comercial & Média & Total & Comercial & Média \\
\hline 'BGH-320' & $56,89 \mathrm{c}$ & $34,56 \mathrm{c}$ & 45,72 & $40,83 \mathrm{a}$ & $33,47 a$ & 37,15 \\
\hline Carmen & 105,46 a & $77,32 \mathrm{a}$ & 91,39 & 41,18 a & 28,28 a & 34,73 \\
\hline Santa Clara & $84,04 \mathrm{~b}$ & $60,17 \mathrm{~b}$ & 72,10 & $30,04 b$ & 24,78 a & 27,41 \\
\hline Média & 83,13 & 57,35 & & 37,35 & 28,84 & \\
\hline C.V. (\%) & 11,98 & 15,35 & & 10,38 & 12,42 & \\
\hline
\end{tabular}

${ }^{1}$ Médias seguidas pela mesma letra na coluna não diferem entre si, ao nível de 5\% de probabilidade, pelo teste Tukey.

compreendê-lo para obter o máximo de produtividade das culturas. No entanto, para se obter sucesso, são necessários o conhecimento e o entendimento dos fatores que afetam a fisiologia e, consequentemente, a produtividade das plantas. Assim, este trabalho teve objetivo de avaliar o efeito dos fatores climáticos luz, temperatura e umidade relativa do ar e de pragas e doenças na produtividade de três genótipos de tomateiro, cultivados em ambiente protegido e no campo.

\section{MATERIAL E MÉTODOS}

Foram conduzidos dois experimentos sendo um em condições de ambiente protegido e outro em nível de campo, no Departamento de Fitotecnia da UFV (MG), utilizando-se o delineamento em blocos casualizados com seis repetições e três tratamentos constituídos pelos genótipos cultivar Santa Clara, híbrido Carmen e o acesso 320 do Banco de Germoplasma de Hortaliças da UFV, codificado como BGH-320. A cultivar Santa Clara foi utilizada por ser a de maior importância do grupo Santa Cruz; o híbrido Carmen por ser o mais cultivado do grupo Salada e o acesso $\mathrm{BGH}$ 320 por destacar-se entre 34 acessos do Banco de Germoplasma de hortaliças da UFV, no que diz respeito à qualidade do fruto (CALIMAN et al., 2002). Os genótipos utilizados apresentam habito de crescimento indeterminado e foram tutorados verticalmente, sendo deixados seis cachos de frutos em cada planta.

$\mathrm{O}$ experimento em ambiente protegido foi conduzido em estufa tipo capela não aquecida, com dimensões de 10 x $40 \mathrm{~m}$ e altura de $5 \mathrm{~m}$, com cortinas laterais retráteis e coberta com filme plástico de 100 micras de espessura. $\mathrm{O}$ solo constituiu-se de um Argissolo Vermelho-Amarelo, cuja análise química revelou os seguintes valores: $\mathrm{pH}=5,4$; $\mathrm{P}=203,1 \mathrm{mg} \mathrm{dm}^{-3} ; \mathrm{K}=138 \mathrm{mg} \mathrm{dm}^{-3}$; $\mathrm{Ca}^{2+}=6,2 \mathrm{cmol}_{\mathrm{c}} \mathrm{dm}^{-3} ; \mathrm{Mg}^{2+}=0,6 \mathrm{cmol}_{\mathrm{c}}$ $\mathrm{dm}^{-3} ; \mathrm{Al}^{3+}=0,0 ; \mathrm{H}+\mathrm{Al}=3,3 \mathrm{cmol} \mathrm{dm}^{-3}$; $\mathrm{CTC}=10,45 \mathrm{cmol}_{\mathrm{c}} \mathrm{dm}^{-3} ; \mathrm{V}=68 \%$ e $\mathrm{MO}=12,23 \mathrm{dag} \mathrm{kg}^{-1}$.

$\mathrm{O}$ experimento no campo foi conduzido sob condições naturais num Argissolo Vermelho-Amarelo Câmbico, lou os valores: $\mathrm{pH}=5,7 ; \mathrm{P}=124,2 \mathrm{mg} \mathrm{dm}^{-3}$; $\mathrm{K}=192 \mathrm{mg} \mathrm{dm}^{-3} ; \mathrm{Ca}^{2+}=4,6 \mathrm{cmol} \mathrm{dm}^{-3}$; $\mathrm{Mg}^{2+}=0,8 \mathrm{cmol}_{\mathrm{c}} \mathrm{dm}^{-3} ; \mathrm{Al}^{3+}=0,0 ; \mathrm{H}+$ $\mathrm{Al}=2,97 \mathrm{cmol}_{\mathrm{c}} \mathrm{dm}^{-3} ; \mathrm{CTC}=8,89 \mathrm{cmol}_{\mathrm{c}}$ $\mathrm{dm}^{-3} ; \mathrm{V}=66 \%$ e $\mathrm{MO}=12,23 \mathrm{dag} \mathrm{kg}^{-1}$.

As mudas foram produzidas em bandejas de isopor de 128 células, onde permaneceram por 20 dias após o semeio, sendo transplantadas, simultaneamente, para o solo dos dois ambientes, em 03/01/2002, em parcelas experimentais constituídas por seis plantas.

Nos dois experimentos utilizou-se o sistema de irrigação por gotejamento e fertirrigações semanais, sendo fornecidos $304 \mathrm{~kg} \mathrm{ha}^{-1}$ de $\mathrm{N}$ e $180 \mathrm{~kg} \mathrm{ha}^{-1}$ de $\mathrm{K}_{2} \mathrm{O}$ no período de janeiro a abril de 2002. O controle de pragas e doenças foi realizado em conformidade com práticas rotineiras de manejo da cultura.

No ambiente protegido foi instalada uma estação climatológica para registrar dados de umidade relativa do ar, temperatura do ar e radiação. Para o cultivo no campo foram utilizados dados climáticos provenientes da Estação Climatológica Principal de Viçosa, $n^{\circ}$ 83642.

A colheita dos frutos produzidos no campo foi iniciada em março e encerrafase Terraço cuja análise química reve- da em maio de 2002 e no ambiente protegido iniciada em março e encerrada em maio.

Após a colheita dos frutos, quando estes atingiram o estádio completamente maduro, foram realizadas a classificação e pesagem para se obter a produção total e comercial. A produção total refere-se ao somatório do peso de todas as colheitas, sendo incluídos todos os frutos, independente da presença de defeitos ou do tamanho. Para a obtenção da produção comercial desconsiderou-se frutos com defeitos (brocados e atacados por fungos ou bactérias) e frutos com diâmetro transversal menor que 40 mm para frutos oblongos ('Santa Clara') e frutos com diâmetro transversal menor que $50 \mathrm{~mm}$ para frutos redondos ('BGH-320' e 'Carmen'), de acordo com a Portaria $N^{\circ} 553$ do Ministério da Agricultura e Reforma Agrária publicada no diário oficial da união de 30 de agosto de 1995.

Para as comparações estatísticas entre as médias de produção total e comercial foi realizada análise conjunta dos dados obtidos em ambos os experimentos (STEEL et al., 1997). As estimativas das médias foram submetidas à análise de variância e teste de Tukey $(\mathrm{P}<0.05)$ no Sistema para Análises Estatísticas SAEG (RIBEIRO JÚNIOR, 2001).

\section{RESULTADOS E DISCUSSÃO}

Houve interação significativa entre ambientes e entre os genótipos para produção total e comercial de frutos. No cultivo protegido, a produção comercial de frutos, quando comparada a total, foi reduzida em aproximadamente $40 \%, 27 \%$ e 29\% para 'BGH-320', 'Carmen' e 'Santa Clara', respectivamente (Tabela 1). No cultivo no campo, a redução na

produção comercial comparada à produção total foi de aproximadamente, $19 \%$; $32 \%$ e $18 \%$ para 'BGH-320', 'Carmen' e 'Santa Clara', respectivamente (Tabela 1). As causas de desclassificação e redução na produção de frutos da categoria comercial no ambiente protegido foram os danos causados pela broca pequena do fruto e a presença de frutos com diâmetro não comercial de acordo com a classificação adotada.

Durante o período de florescimento e frutificação houve alta incidência da 
broca pequena do fruto (Neuleucinoides elegantalis). Esta praga pode causar prejuízos de até $50 \%$, pois os frutos atacados ficam com a polpa destruída e imprestáveis ao consumo (GALLO et al., 2002). Segundo Picanço e Marquini (1999), algumas pragas encontram condições ótimas de desenvolvimento e reprodução em ambiente protegido. Além disso, pode ocorrer maior dificuldade de estabelecimento de populações de inimigos naturais nestes ambientes (PAPADOPOULOS et al., 1997). Esses fatores podem ter favorecido 0 surgimento e a disseminação da referida praga, dificultando seu controle.

Com relação aos frutos com diâmetro inferior ao comercial, sua produção provavelmente é resultado da incapacidade da planta em suprir a quantidade de fotoassimilados necessária ao seu desenvolvimento total, que normalmente ocorre na maioria dos cultivos.

O cultivo no campo teve como causas de desclassificação de frutos os danos da broca do fruto, frutos danificados pelo fungo Phytophthora infestans e frutos com diâmetro não comercial de acordo com a classificação adotada. A baixa eficiência no controle da broca pequena do fruto pode estar relacionada à falhas na aplicação dos inseticidas, favorecendo a infestação e consequentemente, maior perda de frutos. Nunes e Leal (2001), cultivando o tomateiro no campo e em época chuvosa, constataram perda de produção de $17,63 \%$ causada pela broca pequena. Os autores sugerem que a maior ocorrência dessa praga pode estar relacionada à lavagem, pela chuva, dos inseticidas aplicados para controle das pragas.

Além dos danos causados pela broca pequena do fruto, a presença de umidade nas folhas das plantas cultivadas no campo por prolongados períodos de tempo favoreceu a infecção e disseminação do fungo Phytophthora infestans, agente causal da doença 'requeima do tomateiro'. Essa doença é destrutiva pela rapidez de colonização, tanto das folhas e caules quanto dos frutos (KIMATI et al., 1997). Em decorrência desta doença, houve grande desfolha das plantas no campo, com conseqüente redução no seu desempenho produtivo. Dessa forma, a doença contribuiu para a redução

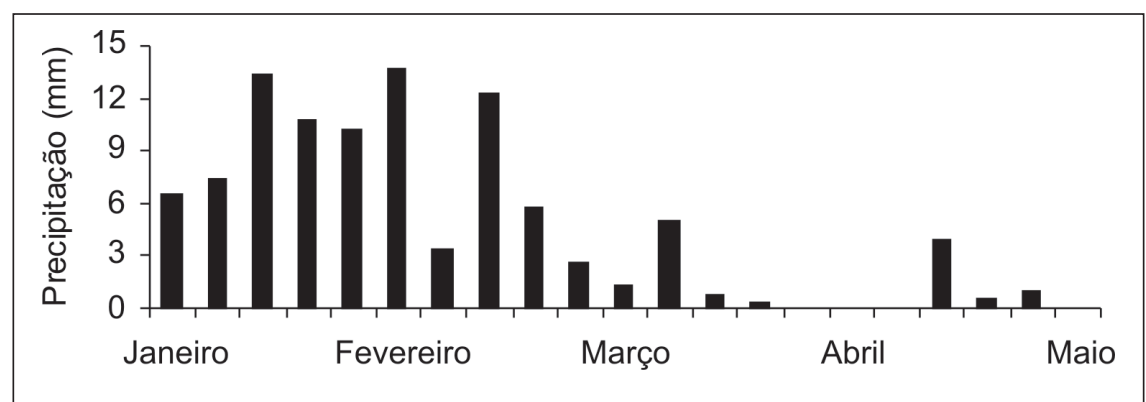

Figura 1. Precipitação média semanal durante a condução do experimento no campo. Viçosa, UFV, 2002.

da produtividade total e comercial dos três genótipos neste ambiente.

Embora não tenha sido feita a comparação entre as médias, observou-se uma tendência dos três genótipos avaliados apresentarem produção total de frutos superior quando cultivados sob ambiente protegido em comparação ao cultivo em campo (Tabela 1), correspondendo a incrementos de $28 \%$; $39 \%$ e $35 \%$, respectivamente, para o acesso BGH-320, híbrido Carmen e cultivar Santa Clara. No ambiente protegido, a produção total de frutos do híbrido Carmen foi significativamente superior às dos demais genótipos, e a da cultivar Santa Clara foi maior que a do acesso BGH-320. No campo, o híbrido Carmen e o acesso BGH-320 apresentaram produção total de frutos semelhantes e superiores à da cultivar Santa Clara (Tabela 1).

Para a produção de frutos comerciais, o desempenho dos genótipos nos dois ambientes de cultivo foi bastante semelhante ao observado para produção total (Tabela 1). No entanto, a produção de frutos comerciais do acesso BGH320 em campo foi muito similar àquela obtida sob cultivo protegido. No ambiente protegido, destacou-se o híbrido Carmen, com produção $77 \%$ e $22 \%$ superior ao 'BGH-320' e 'Santa Clara', respectivamente. No campo, não houve diferença na produção de frutos comerciais entre os genótipos.

Segundo Mello (1988), o emprego de híbridos $\mathrm{F}_{1}$ pode proporcionar aumento na produção de tomate 25 a 40\%, justificando a maior produtividade do híbrido Camen. A produção total do híbrido Carmen no ambiente protegido está próxima a $115 \mathrm{t} \mathrm{ha}^{-1}$ obtida por Fayad et al. (2001) com o híbrido EF-50.
A produtividade média do tomateiro no Brasil é $50 \mathrm{t} \mathrm{ha}^{-1}$ (AGRIANUAL, 2001). Este valor não foi alcançado pelos genótipos cultivados no campo. A intensa precipitação durante o desenvolvimento da cultura contribuiu para a redução da produtividade das plantas neste ambiente. No período de 75 dias contados a partir do transplante, ocorrido no início do mês de janeiro, somaram-se 645 mm de precipitação. A constante ocorrência de chuva proporcionou condições favoráveis ao desenvolvimento de doenças o que, possivelmente, causou redução na produção de frutos (Figura 1).

Além do efeito dos fatores já citados, a intensidade luminosa no campo foi, aproximadamente, $25 \%$ superior à do cultivo protegido (Figura 2A). A luz tem complexa influência no crescimento, desenvolvimento e na produção das culturas. $\mathrm{O}$ aumento da irradiância pode elevar a produção de fotoassimilados e sua disponibilidade para o crescimento da planta e produção de frutos. Entretanto, quando a radiação solar é excessivamente elevada, pode haver aumento na taxa transpiratória da planta resultando em fechamento estomático e diminuição da fotossíntese (ANDRIOLO, 2000). Este fato pode ter ocorrido no campo, já que se tratava de um cultivo de verão no qual as plantas estiveram expostas a elevada radiação solar.

Outro fator climático que pode ter influenciado a produção das plantas foi a umidade do ar. No ambiente protegido foram registrados valores cerca de 10\% superiores aos do campo (Apêndice, Figura 2B). Elevada umidade do ar favorece a expansão foliar do tomateiro (PAPADOPOULOS et al., 1997). Em função da maior área foliar, pode ter ocorrido maior interceptação de energia 

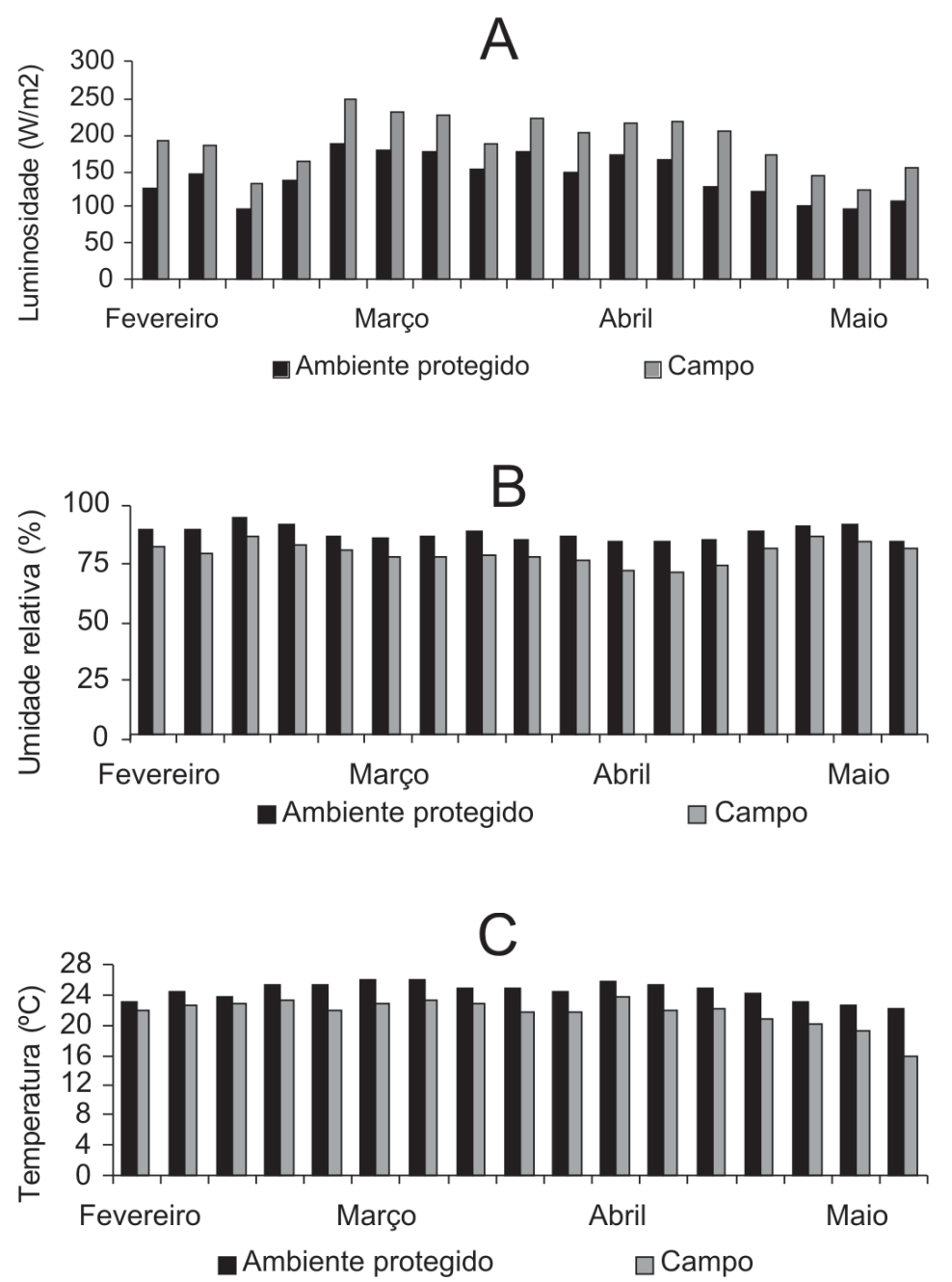

Figura 2. Médias semanais da luminosidade (A), umidade relativa do ar (B) e temperatura (C) no ambiente protegido e no campo durante a condução dos experimentos. Viçosa, UFV, 2002.

luminosa e, como resultado, maior produção de fotoassimilados nas plantas cultivadas no ambiente protegido, resultando em maior produção.

A temperatura do ar no ambiente protegido foi superior à do campo (Figura 2C). Este fator afeta diversos processos biológicos da planta, em especial o crescimento e produção. Pearce et al. (1993), propõem que a razão de crescimento dos frutos do tomateiro é determinada primariamente pela temperatura. Por outro lado, a elevação da temperatura, dentro dos limites favoráveis à cultura, pode resultar no aumento da atividade metabólica do fruto e maior importação de carbono e água. Como resultado, tem-se aumento da expansão e peso do fruto, como observado por Walker e Ho (1977) em frutos de tomate e por Hole e Scott (1984) em ervilha.
A temperatura afeta também outras reações na planta, envolvendo a absorção mineral e o transporte de assimilados, as quais ocorrem diuturnamente (ANDRIOLO, 2000). Quando a temperatura noturna cai para valores abaixo de $18^{\circ} \mathrm{C}$, a velocidade dessas reações diminui, reduzindo também o transporte de fotoassimilados sintetizados durante o dia. Esse transporte somente é retomado no dia seguinte quando a temperatura se eleva novamente, alterando a partição e fixação de matéria seca na planta.

Uma das peculiaridades do ambiente protegido é diminuir grandes oscilações da temperatura entre o dia e a noite. Segundo Papadopoulos e Tissen (1983), quando a temperatura diurna é ótima, a precocidade e produtividade, dependendo do genótipo, é determinada pela temperatura noturna. Esses au- tores sugerem também que quando a temperatura noturna é baixa $\left(8^{\circ} \mathrm{C}\right.$, por exemplo), a frutificação é dependente da temperatura diurna. De Koning (1988) encontrou efeito positivo do aumento da temperatura noturna no tamanho e produção de frutos de tomateiro. Desta forma, a maior temperatura observada no cultivo protegido pode ter contribuído para otimizar a produtividade neste ambiente.

Embora não tenha sido feita a comparação entre as médias, observou-se que o cultivo do tomateiro em ambiente protegido proporcionou maiores produtividades que o cultivo no campo para os três genótipos avaliados, com exceção para a produção comercial do acesso BGH-320, que não diferiu. A maior temperatura nesse ambiente aliada a valores adequados de umidade relativa do ar provavelmente estimularam e aceleraram a velocidade das reações bioquímicas da planta, a absorção, translocação e disponibilização dos nutrientes essenciais ao crescimento, desenvolvimento e produção de frutos. A menor luminosidade neste ambiente provavelmente é compensada pela maior área foliar da planta (maior interceptação de luz), conseqüência da elevada umidade relativa do ar. Apesar das produtividades obtidas no campo estarem aquém da média nacional, os valores obtidos podem ser considerados satisfatórios. Deve-se ressaltar que se tratou de um cultivo de verão, no qual a ocorrência constante de chuva dificulta a obtenção de elevadas produtividades em função da elevada suscetibilidade da cultura a doenças. Com relação aos genótipos, o híbrido Carmen superou os demais no ambiente protegido. $\mathrm{O}$ acesso 'BGH-320', que no ambiente protegido foi inferior aos outros dois genótipos, no campo apresentou produção total superior à da cultivar Santa Clara e semelhante a do genótipo Carmen. No cultivo em campo, a produção comercial não diferiu entre os três genótipos.

\section{AGRADECIMENTOS}

Ao CNPq pela concessão de recursos financeiros e à UFV pela disponibilização da estrutura física e profissional. 


\section{LITERATURA CITADA}

AGRIANUAL 2001. Anuário da Agricultura Brasileira. São Paulo: FNP Consultoria e Comércio, 2004. 512 p.

ANDRIOLO, J.L. Fisiologia da produção de hortaliças em ambiente protegido. Horticultura Brasileira, Brasília, v.18, p.26-33, 2000. Suplemento.

CALIMAN, F.R.B.; MARIN, B.G.; STRINGHETA, P.C.; SILVA, D.J.H.; MOREIRA, G.R.; ABREU, F.B. Caracterização da qualidade de frutos de 32 acessos de tomateiro do Banco de Germoplasma de Hortaliças da UFV. Horticultura Brasileira, Brasília, v.20, n.2, 2002. Suplemento 2. CD-ROM. Trabalho apresentado no $42^{\circ}$ Congresso Brasileiro de Olericultura, 2002.

COCKSHULL, K.E. Crop environment. Acta Horticulturae, n.312, p.77-85, 1992.

DE KONING, A.N.M. The effect of different day/ night temperature regimes on growth development and yield of glasshouse tomatoes. Journal of Horticultural Science, v.63, n.3, p.465471. 1988.

FAYAD, J.A.; FONTES, P.C.R.; CARDOSO, A.A.; FINGER, F.L.; FERREIRA, F.A. Crescimento e produção do tomateiro cultivado sob condições de campo e de ambiente protegido Horticultura Brasileira, Brasília, v.19, n.3, 2001.
GALLO, D.; NAKANO, O.; SILVEIRA, NETO, S.; CARVALHO, R.P.L.; BAPTISTA, G.C.; BERTI FILHO, E.; PARRA, J.R.P.; ZUCCHI, R.A.; ALVES, S.B.; VENDRAMIM, J.D.; MARCHINI, J.C.; LOPES, J.R.S.; OMOTO, C. Entomologia Agrícola. Piracicaba: FEALQ, 2002. $920 \mathrm{p}$ HOLE, C.C.; SCOTT, P.A. Pea fruits extension rate. I. Effect of light, dark and temperature in controlled environment. Journal of Experimental Botany, v.35, p.790-802, 1984.

KIMATI, H.; AMORIM, L.; BERGAMIN FILHO, A.; CAMARGO, L.E.A.; REZENDE, J.A.M. Manual de Fitopatologia. Ceres. 3 ed. São Paulo, v.2, 1997. 774 p.

MANRIQUE, L.A. Greenhouse crops: a reviews. Journal of Plant Nutrition, v.16, p.2411-2477, 1993.

MELLO, P.C.T. Possibilidades e limitações do uso de híbridos $\mathrm{F}_{1}$ de tomate. Horticultura Brasileira, Brasília, v.6, n.2, 1988 .

NUNES, M.U.C.; LEAL, M.L.S. Efeito da aplicação de biofertilizante e outros produtos químicos e biológicos, no controle da broca pequena do fruto e na produção do tomateiro tutorado em duas épocas de cultivo e dois sistemas de irrigação. Horticultura Brasileira, Brasília, v.19, n.1, 2001. PAPADOPOULOS,

A.P.; PARARAJASINGHAM, S.; SHIPP, J.L.; JARVIS, W.R.; JEWETT, T.J.; CLARKE, N.D. Integrated management of greenhouse vegetable crops. Horticultural Reviews, v.21, p.1-39, 1997.
PAPADOPOULOS, A.P.; TISSEN, H. Root and air temperature effects on the flowering and yield of tomato. Journal American Society for Horticultural Science, v.108, p.805-809, 1983.

PEARCE, B.D.; GRANGE, R.I.; HARDWICK, K. The growth of young tomato fruit. II. Environmental influences on glasshouse crops grown in rockwool or nutrient film. Journal of Horticultural Science, v.68, p.12-23, 1993.

PICANÇO, M.; MARQUINE, F. Manejo integrado de pragas de hortaliças em ambiente protegido. Informe Agropecuário, Belo Horizonte, v.20, p.126-133, 1999.

RIBEIRO JÚNIOR, J.I. Análises estatísticas no SAEG. Viçosa: UFV, 2001. 301 p.

STEEL, R.G.D.; TORRIE, J.H.; DICKEY, D.A. Principles and procedures of statistics: a biometrical approach, 3. ed. New York: McGrawHill, 1997. $666 \mathrm{p}$

VIDA, J.B.; ZAMBOLIM, L.; VALE, F.X.R.; COSTA, H. Manejo de doenças em cultivos protegidos. In: ZAMBOLIM, L. (Ed.). Manejo integrado e Fitossanidade: cultivo protegido, pivô central e plantio direto. Viçosa, 2001. 722 p.

WALKER, A.J.; HO, L.C. Carbon translocation in the tomato: Carbon import and fruit growth. Annals of Botany, v.41, p.813-823, 1977. 